\title{
Implication of cultural factors in spatial patterns of stunting among the three main Frafra groups in Upper East Region of Ghana
}

\author{
Christopher Sormiteyema Boatbil ${ }^{1}$, Chris Bambey Guure ${ }^{2, *}$ \\ ${ }^{1}$ Department of Liberal Studies, School of Applied Sciences and Arts, Bolgatanga Polytechnic, Ghana \\ ${ }^{2}$ Department of Biostatistics, School of Public Health, University of Ghana, Legon, Accra, Ghana
}

Email address:

csboatbil@yahoo.com (C. S. Boatbil),chris@chrisguure.com (C. B. Guure)

\section{To cite this article:}

Christopher Sormiteyema Boatbil, Chris Bambey Guure. Implication of Cultural Factors in Spatial Patterns of Stunting among the Three Main Frafra Groups in Upper East Region of Ghana. International Journal of Nutrition and Food Sciences. Vol. 3, No. 2, 2014, pp. 37-43. doi: 10.11648/j.ijnfs.20140302.14

\begin{abstract}
Background: Child malnutrition is a public health problem in Ghana. Focused on three sub-districts of Gurene, Talensi and Nabdam in the Upper East Region of Ghana, this study examines how cultural factors occasion spatial patterns of stunting. Method: A questionnaire for 300 respondents were equally shared among sub-districts. Result: The study indicates significant spatial differences as Nabdam was very high (50\%), Talensi high (37\%) and Gurene (21\%). Also, children of single mothers were better nourished followed by children of widows and those married. For all well-nourished children 43.4\% lived in the Gurene area, $32 \%$ in Talensi area and $24.6 \%$ in Nabdam area. Factors such as ethnicity, religion, number per siblings and number of (women) were found to significantly contribute either directly or indirectly to stunting levels. Conclusion: The study found out that, there is enough evidence indicating that significant variations of under-five stunting exist among the three main sub-ethnic groups. All the variables under study had positive correlations with stunting among children under five years of age. However, the effects of these factors on stunting were enhanced by other factors including mothers' education and age.
\end{abstract}

Keywords: Malnutrition, Children, Stunting, Sub-Districts, Gurene, Talensis, Nabdams

\section{Introduction}

Child malnutrition is a serious and most widespread public health problem in the developing world and also the most lethal nutritional disorder among children, Oppong (1999). Malnutrition means "badly nourished" but is more than just a measure of what we eat or fail to eat. Clinically, it is when the body's nutritional reserves are depleted and insufficient to meet the day-to-day needs or added metabolic stress, Williams (1999). Two broad types of malnutrition exist. The types are micronutrient and macronutrient deficiencies malnutrition. The latter, aspect commonly studied in the social sciences is known as protein-energy malnutrition (PEM) and is reflected in kwashiorkor, marasmus or marasmic-kwashiorkor. PEM has three indices namely stunting, underweight and wasting. For the purposes of this study, the term stunting is loosely used to mean PEM.

Protein-energy malnutrition is the inadequate intake of protein or energy which causes severe stunting mostly in the first two years of life. It makes the body to utilize stored tissues of energy when nutrients supply is inadequate. Consequently, the body loses fat, muscle strength, and develops a skeletal appearance visibly noticed in the hands and the temporal muscle in front of and above each ear. In marasmic conditions the child experiences unbearable weaknesses, frequent sicknesses, and anorexia and develops dry and flabby skin, silver hair, hypothermia, reduced activity, mental retardation among others (Morley, 1994; Azure, 2003).

Children require higher protein and energy needs and are more susceptible to infections compared to adults and therefore constitute the most vulnerable section of society. Good nutrition is thus imperative for child growth and gives antibodies to overcome infections. For instance, a child's brain grows up to $80 \%$ of adult size in the first three years of life whilst events in its growth occur at defined times with 
little compensation for detractions (Ghosh, 1995; De Blij, 1996).

According to Andrews and Dino (2003), about 181.9 million $(32 \%)$ children were malnourished in the third world. The causes of child malnutrition can be grouped under three main levels namely direct (inadequate food intake and diseases), underlying (food security at the household level, public health, social care and environment and basic causes) and the basic (political, economic, socio-cultural and physical environment) factors.

Spatial and cultural variables are important aspects sometimes considered when analyzing causes of child malnutrition or PEM. Studies show that in Sudan and the middle belt of Nigeria, cultural causes included decline in breastfeeding, rising bottle-feeding, lack of supplementary feeding, unequal intra-family food distributions, large family sizes and low levels of immunizations. To ameliorate the problem, family stability, responsible parenthood and small family sizes through culturally accepted family planning methods were emphasized (Ighogboja, 1992 and Taha 1979). Spatially, the percentage of malnourished preschool children among specific tribes in India are different. For instance, among the three sects of Saurias, Mals and Kumarbhargs, children malnourished were $89 \%$, $92 \%$ and $93 \%$ respectively (Choudhary, 2001). Also, Mata (1980), found that whilst traditional populations living in close proximity with nature in Costa Rica and Guaymi aborigines in scattered dwellings in the forests and jungles of Panama had satisfactory nutrition, the Maya Cakchiquel Indians who live in better homes experienced malnutrition. Similarly, children of the Gyidim and Sukuumu communities in the Asante Akim north district of Ghana showed different stunting levels though not significant (Azure, 2003).

The effects of child malnutrition are many including retardation of physical growth, visual impairment, ill-health and consequently death. It is for this reason that many governments in the developing world are trying to resolve the problem. Though the potential of culture to induce or prevent the incidence and magnitude of PEM cannot be underestimated as earlier discussed, it has not been widely explored in tandem with spatial dimensions.

\subsection{Problem Statement}

Good nutrition and childcare are fundamental to the development of children and the reverse is true. PEM leads to school dropouts, mental retardation, illness, death and consequently general underdevelopment of affected societies (Oppong, 1999; Agyei-Mensah 1999; De Blij 1996; PRB 1991; Jansen, 1977). This study focuses on stunting which is one of the indices of PEM. Stunting is an index of linear growth retardation reflecting a failure to receive adequate nutrition over long periods of time and can be affected by recurrent and chronic illnesses. It shows a long-term effect of malnutrition and does not differ due to recent dietary intake. Stunting in the Upper East Region (U.E.R.) of Ghana is observably high (BRHA, 2004). For example, it was $26.1 \%$ in $1993,36 \%$ in $1998,31.7 \%$ in 2003 , and $36 \%$ in 2008 (GSS, 1993; 1998; 2003; 2008). However, spatial differences exists. Reports show pre-harvest levels for Talensi and Nabdam were $52 \%$ and $72.9 \%$ whilst post-harvest levels were $47.9 \%$ and $55.6 \%$ respectively (Nabila, 1992). This deserves the attention of central government, local authorities and interested non-governmental organizations. The need to find a solution to the problem of stunting initially requires that its levels are established in geographic regions and causes identified in order to provide targeted solutions. The factors responsible for these variations may be varied but this study focuses on finding how cultural factors help in explaining the spatial patterns of PEM that exist in the study area.

\section{Methods}

This cross-sectional study of three sub districts in Upper East Region of Ghana was conducted to assess the role of cultural factors in the spatial patterns of child malnutrition. Stunting, technically, a composite of underweight and wasting, as an index of child malnutrition. Based on Heightfor- Age, a child is stunted if anthropometric measurement is $<2$ SD from the median of the NCHS. In this study, $<3$ SD refers to the severe stunting, $<2 \mathrm{SD}$ the moderate stunting $<$ 1SD mild stunting and $>1$ SD the well-nourished. Both primary and secondary data sources were employed. The main tools for the study were a detailed set of structured household questionnaire, a bathroom scale, an infantometer and, EPI-info software. A questionnaire which was administered to mother/caretaker of study children aged 0-59 months recorded children age and heights and elicited information on five main variables of ethnicity, marital status of mothers, siblings per mother, religion and number of rivals. The sample size which was determined using Snedecor and Cochran (1989) formula, produced a sample size of 89 subjects for each sub-district and approximated to 100. Adopting a multi-stage sampling technique, the study area was clustered into Frafra (i.e. Gurene), Talensi and Nabdam Sub Districts based on cultural variations. Next, simple random sampling was used to select four localities from each of the sub districts whilst systematic sampling was used to select compound houses in each locality. Furthermore, purposive sampling was used to select households on houses with women who had children between 0-59 months. If the number of households was more than one, a simple random method was applied to select one. Mothers within the selected household were also selected via simple random method if they were more than one. To enter the data, EPI-INFO version 6 and SPSS version 16 (statistical package) were used. Analysis of data was largely descriptive in nature. Chi-square was used to determine significant differences among sub-districts whilst correlations were employed to examine degree of relationships. One-way ANOVA was also used to determine the standard deviation of variables such as stunting levels, education and religion among the zones. 


\subsection{Hypotheses}

Null

i. There is no difference in the levels of stunting over space.

ii. There are no significant differences in stunting levels among religious groups

iii. Alternative

iv. There is significant difference in the levels of stunting over space.

v. There are significant differences in stunting levels among religious groups

\section{Results}

\subsection{Spatial Patterns of Child Malnutrition in Study Area}

The percentage of children under the categorization will be matched with WHO classification of $(<20 \%=$ low, $20-29 \%=$ moderate, $30-39 \%=$ high and $\leq 40 \%=$ very high) in order to describe the levels.

\subsection{Differences among Sub Districts}

The overall level of stunting was high and spatially varied. About $36 \%$ of children were stunted and $8 \%$ of them considered as severely stunted. The Gurene Sub District is better, followed by the Talensi and Nabdam Sub Districts respectively. Stunting level was very high $(50 \%)$ in the Nabdam Sub District, high (37\%) in Talensi Sub District (37\%) and moderate (21\%) in the Gurene Sub District. Fig 1, presents the percentage distributions of stunting observed during the study. The patterns of stunting types is indicated in fig 2 from which it can easily be observed that the Gurene Sub-District had the highest level of well-nourished and smallest severe stunting levels for children under five. About $43.4 \%$ of all well-nourished children lived in the Gurene Sub District, 32\% in the Talensi Sub District and $24.6 \%$ in Nabdam Sub District. The Gurene Sub District had $37.1 \%$ of the mildly stunted whilst Talensi and Nabdam had $34.3 \%$ and $28.6 \%$ respectively.

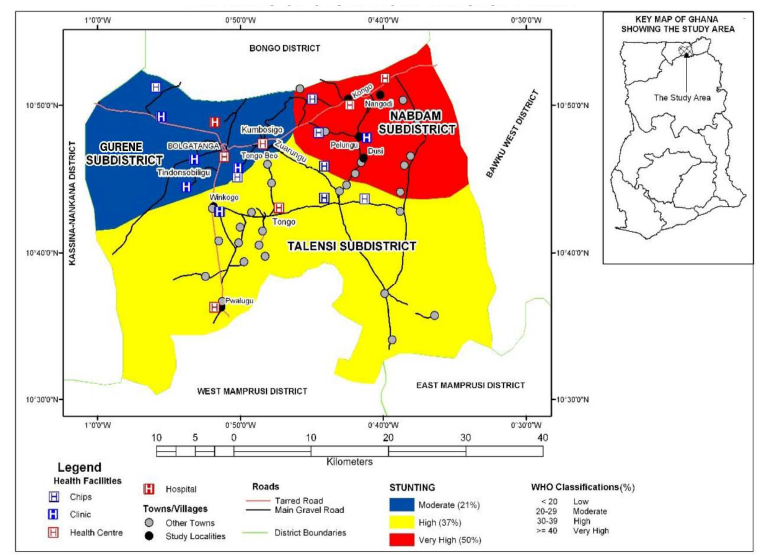

Fig 1. patterns of stunting in the study area

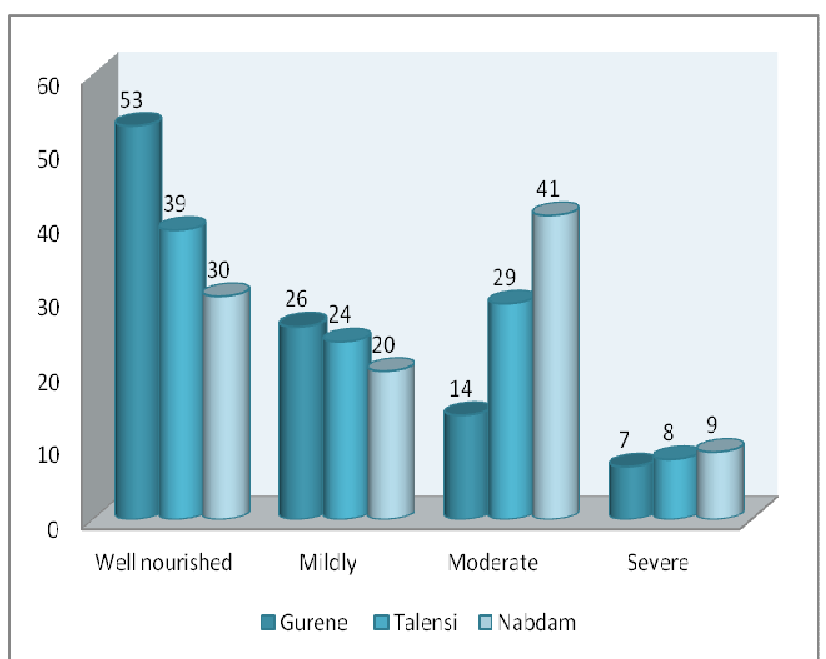

Fig 2. Spatial distribution of under-five categories of stunting (\%)

A chi-square value was derived to determine significant differences in stunting among sub-districts. The calculated value was 11.72 which is higher than the critical value of 5.991 at 2 degrees of freedom indicating significant differences among the three sub districts. We therefore reject the claim that there are no significant differences in terms of stunting among the sub districts at 5\% significance level.

\subsection{Relationships between Cultural Factors and Spatial Patterns of Stunting}

The cultural factors to be discussed include marital status, ethnicity, religion, number of siblings per woman and number of rivals.

\subsubsection{Marital Status}

Marriage as observed from the study was popular among respondents and shows why a large percentage of mothers were either married or ever married. Married mothers were (88\%) with single mothers being only $4.3 \%$. Widows constituted $7.3 \%$ whilst the divorced or separated formed an insignificant $0.3 \%$ of the sample. In terms of stunting, children of single mothers were better nourished followed by children of widows, the married and the divorced or separated respectively. Fig 3, shows the relationship in percentages between marital status and stunting in the study area. The levels of stunting among children of separated or divorced mothers were very high whilst those with married, widowed and single mothers registered high levels of stunting.

Married respondents who formed the majority were almost equally distributed among the sub districts. They were $87 \%, 88 \%$ and $89 \%$ respectively for the Nabdam, Gurene and Talensi Sub Districts respectively. There is therefore no basis to conclude that the marital status of mothers had any influence on the spatial differences in the magnitude of stunting. 


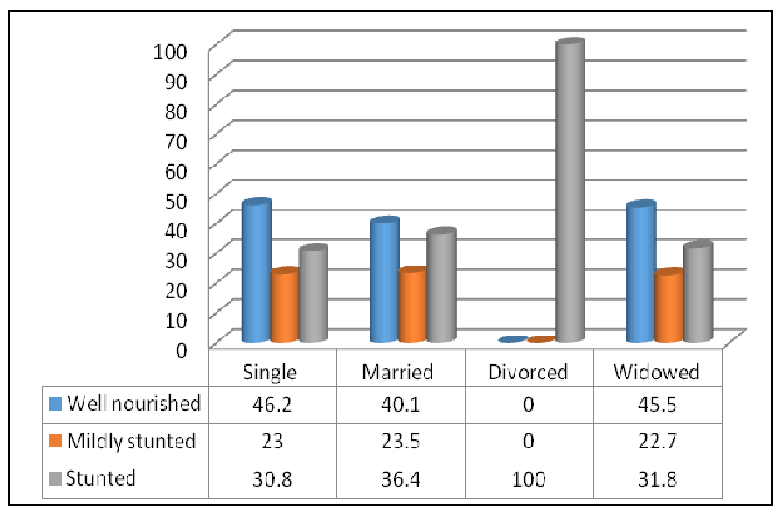

Fig 3. Mother marital status and pattern of under-five (5) stunting in (\%)

Table 1. Influence of ethnicity on children's stunting status

\begin{tabular}{ccccc}
\hline \multirow{2}{*}{$\begin{array}{c}\text { Ethnicity of } \\
\text { mothers }\end{array}$} & \multicolumn{3}{c}{ Stunting \% } & Total \\
\cline { 2 - 4 } & $\begin{array}{c}\text { Well } \\
\text { nourished }\end{array}$ & $\begin{array}{c}\text { Mildly } \\
\text { stunted }\end{array}$ & Stunted & \\
\hline Talensi & 37.8 & 25.6 & 36.7 & 90 \\
Nabdam & 27.7 & 23.3 & 49 & 94 \\
Gurene & 54.1 & 18 & 27.9 & 61 \\
Akan & 33.3 & 33.3 & 33.3 & 3 \\
Dagomba & 54.5 & 18.2 & 27.3 & 11 \\
Others & 53.7 & 26.8 & 19.5 & 41 \\
$\begin{array}{c}\text { Number of } \\
\text { children }\end{array}$ & 122 & 70 & 108 & 300 \\
\hline
\end{tabular}

\subsubsection{Ethnicity}

The respondents were differently composed in terms of ethnicity with different levels of malnutrition. However 'others' included such tribes as Kassenas, Dagartis, Builsas, Moshis and Kusasis. Out of the total sample size, Nabdams formed the majority with $31.3 \%$ followed by Talensis with $30 \%$, Gurenes with $20.3 \%$ and other tribes were $6 \%$. How cosmopolitan each sub district was, determined the proportion of its main ethnic group and hence stunting levels. Generally, Nabdam children had the worst levels of stunting followed by children of Talensis and Akans. Nabdams had a very high level of stunting compared with high levels among Talensis and Akans children. On the other hand, both Gurene and Dagombas had moderate levels whilst other tribes had low level of stunting. Table 1, illustrates the proportions of malnourished children among the various ethnic groups covered in the survey. For the main spatial groups under study, stunting was highest among Nabdam, Talensi and Gurene children respectively. The fact that children of each sub ethnic group dominated in their sub district implies that the ethnicity of indigenes explained the spatial pattern of stunting.

\subsubsection{Religion}

Three major religions namely Christianity, Islam and African Traditional religion were identified in the study area. Over half of the respondents (women) were Christians even though majority of their husbands practiced the traditional faith. There was a preponderance of Christian mothers partly due to the distribution of food by the Catholic Church during hunger periods and recent proliferation of protestant churches whose services are characterized by entertaining musical displays. About $32 \%$ of respondents were Muslims and $16 \%$ were Traditional believers. Each group had different levels of child stunting due in part to different beliefs and practices. Children of Christian mothers had better stunting levels, with children of Muslims and Traditional children following in a descending order. Stunting for Christian children was at a moderate level, Muslim children, high level and those of Traditional religion very high level. The calculated chi-square is 10.27 , higher than the degrees of freedom (5.991) and so with the confidence level of $95 \%$, we can therefore state that there is enough evidence at 5\% level to support the alternative hypothesis that significant differences in the levels of stunting exist among the religious groups. Fig 4, illustrates the effect of respondents' religion and child stunting in the study area.

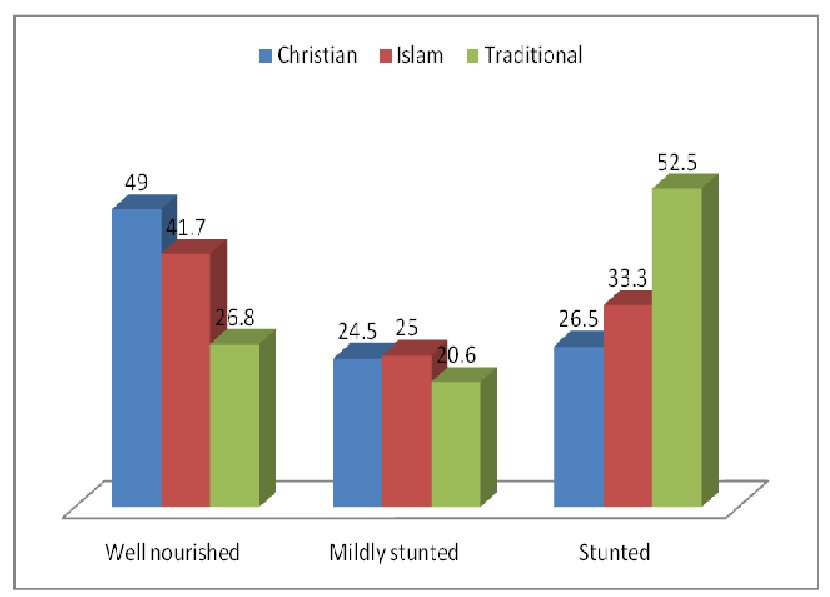

Fig 4. Mothers' religion and pattern for under five (5) stunting in (\%)

Religion played a significant role in explaining the variations of PEM among the sub districts of the study area as well as between urban and rural areas. From the survey, the Gurene Sub District had a substantial share of both Christians and Muslims. They constituted 58\% and 35\% respectively with only $7 \%$ being Traditional believers. On the other hand, the Talensi Sub District had 53\% Christians, 12\% Muslims and 35\% Traditional believers whilst Nabdam Sub District had 44\%, 1\% and 55\% respectively. From Table 2 , it is observed that majority of Christians obtained high levels of education whiles no one practicing traditional religion in so far as this study is concern had any form of post-secondary and/or tertiary education. Generally, table 3 shows that the standard deviation of the variable education is widely spread among the zones compared to religion. In terms of education, the Nabdam zone has the widest spread, followed by Talensi and Gurene. For education, standard deviation is greatest for Gurene and followed by Talensi and Nabdam. 
Table 2. Percentage of each religious group at each level of education

\begin{tabular}{cccccccc}
\hline Religion & $\begin{array}{c}\text { No } \\
\text { edu }\end{array}$ & $\begin{array}{c}\text { Pri } \\
\text { m. }\end{array}$ & $\begin{array}{c}\text { Mid/ } \\
\text { JSS }\end{array}$ & $\begin{array}{c}\text { SS/O. } \\
\text { L }\end{array}$ & $\begin{array}{c}\text { Post } \\
\text { sec }\end{array}$ & $\begin{array}{c}\text { Terti } \\
\text { ary }\end{array}$ & Y \\
\hline $\begin{array}{c}\text { Christia } \\
\text { ns }\end{array}$ & 42.2 & 51.5 & 73 & 60.4 & 76.7 & 66.7 & 155 \\
Muslims & 12 & 12.1 & 16.2 & 29.2 & 23.1 & 33 & 48 \\
$\begin{array}{c}\text { Traditio } \\
\text { nal }\end{array}$ & 78.4 & 12.4 & 4.1 & 5.2 & 0 & 0 & 97 \\
X & 166 & 33 & 37 & 48 & 1 & 3 & 300 \\
\hline
\end{tabular}

Table 3. Standard dev. among zones for each religious group and level of education

\begin{tabular}{cccccc}
\hline \multirow{2}{*}{ Zones } & $\mathrm{N}$ & \multicolumn{2}{c}{ Mean } & \multicolumn{2}{c}{ Std. Deviation } \\
& & Rel. & Edu & Rel. & Edu \\
\hline Gurene & 100 & 1.49 & 2.73 & .628 & 1.523 \\
Talensi & 100 & 1.82 & 1.86 & .925 & 1.247 \\
Nabdam & 100 & 2.11 & 1.59 & .995 & 1.026 \\
Total & 300 & 1.81 & 2.06 & .897 & 1.369 \\
\hline
\end{tabular}

\subsubsection{Siblings per Woman}

Culturally, the penchant for many children in the study area is rife for reasons of social status and labour pools on family farms. However, few mothers had large numbers of children. This phenomenon can be explained by the relatively large number of young women interviewed. Mothers or caregivers with one to four children formed the majority of respondents $(77.7 \%)$ and those with five children or more formed about $22.3 \%$ of the entire sample size. Notwithstanding this, stunting increased with increasing number of siblings. From Table 3, the level of stunting was low for single and two siblings, moderate among children of three siblings and very high for children of four siblings and above.

Table 4. Number of siblings per woman and stunting

\begin{tabular}{ccccc}
\hline \multirow{2}{*}{$\begin{array}{c}\text { Number of } \\
\text { siblings }\end{array}$} & $\begin{array}{c}\text { Well } \\
\text { nourishe } \\
\text { d }\end{array}$ & $\begin{array}{c}\text { Mtunting \% } \\
\text { Mildly }\end{array}$ & Stunted & Total \\
\hline One & 57.9 & 26.3 & 15.8 & 57 \\
Two & 57.9 & 24.4 & 12.8 & 78 \\
Three & 45.6 & 29.8 & 24.6 & 57 \\
Four & 24.4 & 29.3 & 46.3 & 41 \\
Five & 8.3 & 11 & 80.5 & 36 \\
Six & 4.8 & 14.3 & 80.9 & 21 \\
Seven & 0 & 0 & 100 & 9 \\
Eight + & 0 & 0 & 100 & 1 \\
$\begin{array}{c}\text { Number of } \\
\text { children }\end{array}$ & 122 & 70 & 108 & 300 \\
\hline
\end{tabular}

Table 5. Standard deviation among zones for stunting

\begin{tabular}{cccc}
\hline Zones & $\mathrm{N}$ & Mean & Std. Deviation \\
\hline Gurene & 100 & .75 & .947 \\
Talensi & 100 & 1.06 & 1.003 \\
Nabdam & 100 & 1.29 & .998 \\
Total & 300 & 1.03 & 1.004 \\
\hline
\end{tabular}

The distribution of siblings per mother within each sub district offers explanations to rural-urban dichotomy in the magnitude of stunting in the study area. It cannot, however explain the differences between Talensi and Nabdam Sub Districts because number of siblings did not differ significantly between them. In the Gurene Sub District, about $70 \%$ of mothers had between one and three children, $26 \%$ had between four to six children and $4 \%$ had seven children and above. Also about $60 \%$ mothers had one to three children in the Talensi and Nabdam Sub Districts. The differences in the levels of PEM between the two sub districts might rather be due to non-availability of food and parents educational background. This is illustrated in Table 3 where the Gurene's have majority of Christians who are highly educated and very well informed as compared to the Talensi and Nabdam Sub Districts. The difference in standard deviation in table 5 indicates stunting in Talensi zone has a wider spread compared to both Gurene and Nabdam zones whilst that of Nabdam slightly exceeds the Gurene zone.

\subsubsection{Number of Rivals}

The study revealed that, majority of mothers or caregivers (71.7\%) did not have rivals. Mothers with a single rival constituted $14.3 \%$ and those with two, three and four or more rivals were $9 \%, 1.7 \%$ and $3.3 \%$ respectively. Higher levels of stunting were associated with numerous rivals and vice versa but results did not necessarily show that stunting levels correspondently increased with increasing number of rivals. Figure 5 , shows the link between number of rivals and children's nutritional status in the study area.

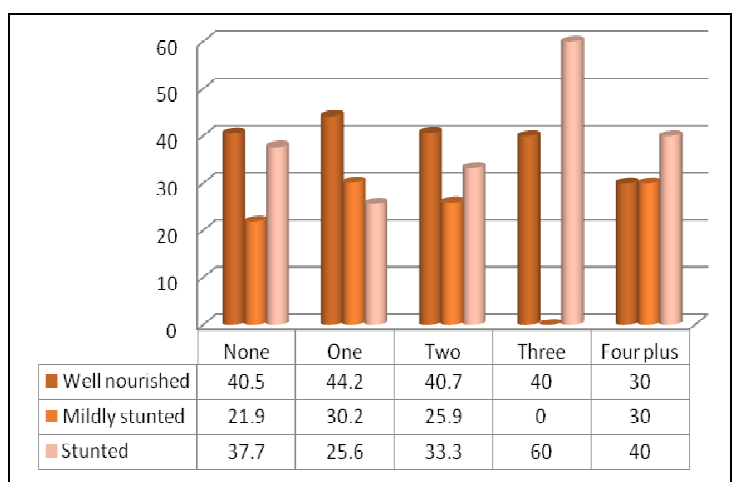

Fig 5. Number of (mother's) rivals and pattern of under-five (5) stunting in (\%)

Children whose mothers had two or no rival recorded high level of stunting; those whose mothers had one rival had moderate level whilst those with three or more had very high 
levels. The number of rivals does not explain the pattern of stunting because mothers without rivals were more in the Nabdam Sub District whilst those with four or more were greatly found in the Gurene Sub District but with better socio-economic conditions. This could be influenced by the high level of Muslim religion that practicing polygamy in the Gurene Sub District.

\section{Discussions}

The study found that stunting to be spatially varied with significant differences. This appears to be supported by the findings reported by other authors of spatial variations in malnutrition or specifically stunting. Nabila (1992) found variations in pre-harvest stunting among Talensi and Nabdams were $52.6 \%$ and $72.9 \%$ whilst post-harvest levels were $47.9 \%$ and $52.6 \%$ respectively. The work of Mata (1980) also indicated that ethnicity and locations are responsible for spatial differences in the magnitudes of PEM in Costa Rica. For instance, the Guaymi aborigines living in scattered dwellings rather had satisfactory nutrition than the Maya Cakchiquel Indians who live in better homes Choudhary (2001).

- The differences in the PEM levels among children of Christians, Muslims and Traditional believers are due to Muslim prohibition of pork and chicken among some Traditional believers. The poor ones could neither afford other sources of animal protein to supplement their diets. Another contributory factor was particularly the deplorable dwellings of majority of Muslims especially those who stay in the Zongo community in the Gurene sub district compared with most Christians who stayed in relatively better areas. There were also more women with secondary education particularly among Christians and Muslims than those practicing Traditional religion.

- Religion played a significant role in the variations of the PEM among the sub districts of the study area as well as between urban and rural areas due to its spatial differentials. From the study, the Gurene sub district had a substantial share of both Christians and Muslims. They constituted $58 \%$ and $35 \%$ respectively with only $7 \%$ being Traditional believers. On the other hand, the Talensi sub district had 53\% Christians, 12\% Muslims and 35\% Traditional believers whilst Nabdam sub district had $44 \%, 1 \%$ and $55 \%$ respectively. Also a study of two communities (Gyidim and Sukuumu) in the Asante Akim north district of Ghana by Azure (2004), confirms the finding that religious beliefs have significant correlations with stunting.

- In this study, children of Nabdams and Talensis were hardest hit because most of them are in rural areas where farming is the main occupation and people are unable to meet all food needs. Furthermore, parents in these sub districts are illiterates, poor and have little access to modern social facilities. From the study, except the Gurene sub district where children of indigenes were less than half of the sample (43\%), because of a significant mixture of several ethnic groups, in both sub-districts of Nabdams and Talensis, children of indigenes dominated with $89 \%$ and $78 \%$ respectively. With a relatively more cosmopolitan area, the Gurene area suffered less stunting compared to the others. This also explains the rural-urban differences in malnutrition within the study area.

- Paradoxically, married mothers who had husbands to provide food and finance were not significantly better nourished than others signifying that irrespective of the presence of fathers, women's economic statuses play crucial roles in determining children's nutritional statuses. Children of married mothers were not better nourished because such mothers formed the bulk with a many of them being illiterates and suffering from poverty. The spatial

- The proportions of various groups of mothers not married each constituted minute percentages of the total sample and therefore could not have significantly influenced the spatial patterns of PEM in the study area.

\section{Conclusions}

The study sought to understand three issues. The first was to determine magnitudes of stunting among the three sub districts of the Frafra people. The second was to find out if there were significant spatial differences. The third was to explore whether cultural variables influenced stunting and further explain spatial variations of three ethnic groups. The following observations were arrived at:

$\checkmark \quad$ Stunting levels among children below five years among the broad Frafra ethnic groups are high

$\checkmark \quad$ There is evidence indicating that significant variations of under-five stunting exist among the three main sub-ethnic groups (Gurene, Talensi sand Nabdams) of Upper East Region of Ghana.

$\checkmark \quad$ All the variables under study had positive correlation with stunting among children under five years of age. However, the effects of these factors on stunting were enhanced by other factors including the mothers' education and age.

$\checkmark \quad$ The factors though had influence on the levels of under-five stunting, only some could explicitly be used to explain the spatio-ethic variation in the levels of stunting among the three identified sub-districts of Gurene, Talensi and Nabdam.

\section{Recommendations}

$>$ There should be public education about the problem of under-five stunting in communities of the three sub-districts of the Frafra area. Communications of these messages should be done in local dialects to enable audience to fully appreciate the magnitude of the problem 
> Solutions to the problem should be geographically targeted. For instance, the allocation of resources in terms of personnel and finances to combat under-five stunting should be based on the magnitude of stunting in each sub-district

$>$ Different weights should apply to factors that explain the spatial variations in the magnitudes of stunting of the various sub-districts. This could be used as the bases for allocation of resources to different geographical areas to stem the problem of stunting.

$>$ Similar studies among other ethnic groups in Upper East Region and expansion of the number of cultural factors should be considered in future studies.

\section{Competing Interests}

The authors declare that they have no competing interests.

\section{References}

[1] Agyei-Mensah, S. (1999). Infant Nutritional Trends in Sub-Saharan Africa: Evidence from Demographic and Health Surveys 1986-1998, Research Review series, 13: $1-11$.

[2] Andrews, L. and Dino, S. (2003). Protein-Energy Malnutrition. The World Health Organization, http://www.emedicine.com/derm/topic797/2003.

[3] Azure, R. A. (2003). Comparative study of nutritional status of children 0-59 months of age in two communities in Agogo, Asante Akim North District. A Dissertation Submitted to the School of Public Health, University of Ghana, for the Award of Master of Public Health Degree. Unpublished.

[4] BRHA [Bolgatanga Regional Health Administration] (2004). Second Half Year Program Implementation Report on Supplementary Feeding in Upper East Region, July-December, Regional Annual Health Review of Ghana Health Service, U. E. R. Ghana.

[5] Choudhary, R. P. (2001). Anthropometric Indices of Nutritional Deficiency Sign in Pre-School Children in India, Anthropol Anz. 59: 61-71.

[6] De Blij, H.J. (1996). Human Geography: Culture, Society and Space. John Wiley \& Sons, Inc.

[7] Ghana Statistical Service [GSS] and Macro International Inc. [MI] (1993). Ghana Demographic and Health Survey. Calverton, Maryland: GSS and MI
[8] Ghana Statistical Service (GSS) and Macro International Inc. [MI] (1998). Ghana Demographic and Health Survey. Calverton, Maryland: GSS and MI.

[9] Ghana Statistical Service (GSS), Noguchi Memorial Institute for Medical Research (NMIMR), and ORC Macro (2003). Ghana Demographic and Health Survey. Calverton, Maryland: GSS, NMIMR, and ORC Macro.

[10] Ghana Statistical Service (GSS), Ghana Health Service (GHS), and ICF Macro (2008). Ghana Demographic and Health Survey. Accra, Ghana: GSS, GHS, and ICF Macro.

[11] Ghosh, S. (1995). Nutrition of children under five, Health Care of Women and Children in Developing Countries $\left(2^{\text {nd }}\right.$ edition).

[12] Ighogboja, S. I. (1992). Some Factors Contributing to Protein-Energy Malnutrition in the Middle Belt of Nigeria, E. Afr Med J, 10: 69.

[13] Jansen, A. A. (1977). Malnutrition and Children Feeding Practices in Western Samoa, J Trop Paediatr. 23: 293-306.

[14] Lisa, C. S. and Haddad, L. (2000). Overcoming Child Malnutrition in Developing Countries: Past Achievements and Future Choices. International Food Policy Research Institute. At: http//www.ifpri.org/2020/briefs/number64/

[15] Morley D. (1994). Malnutrition in Children. In: Lankinen KS, Bergström S, Mäkelä PH and Peltomaa M (Eds.): Health and Disease in Developing Countries. The Macmillan Press Limited, London, U.K. p. 297-304.

[16] Nabila, J.S. (1992). Population, Health and Migration: A Socio-Economic Survey in the Upper East Region with Reference to Drought and Desertification Control in Ghana. Final Report Submitted to the Environmental Protection Council of Ghana. Department of Geography and Resource Development, University of Ghana - Legon, 1992, 9-51.

[17] Oppong, C. (1999). Infants' Entitlements and Babies' Capabilities: Explaining Infant Hunger, Research Review (New Series), Institute of African Studies, University of Ghana, Legon, 15, 2

[18] Population Reference Bureau [PRB] (1991). Family Planning Saves Lives ( $2^{\text {nd }}$ Edition). Population Reference bureau, Washington, D. C.

[19] Taha, S. A. (1979). Ecological Factors Underlying Protein-Caloric Malnutrition in an Irrigated Area of Sudan, Ecol Food Nutr, 7: 193-201.

[20] Williams, S. R. (1999). Essentials of Nutrition and Diet Therapy $\left(6^{\text {th }}\right.$ Edition). Mosby - Year Book, Inc. 